\title{
Viviendo de la Sociología: egresados(as) de la Universidad Nacional de Colombia y mercados parciales de trabajo'
}

\author{
Living off Sociology: Graduates from \\ Universidad Nacional de Colombia and \\ Labor Market Segments
}

\section{Vivendo da sociologia: graduados (as) da Universidad Nacional de Colombia e mercados parciais de trabalho}

William Mauricio Beltrán ${ }^{2}$

Profesor Asociado de la Universidad Nacional de Colombia, Bogotá, Colombia wmbeltranc@unal.edu.co

\section{Darío Berrío Gil}

Profesional de apoyo en el Ministerio de Educación Nacional, Bogotá, Colombia dsberriog@unal.edu.co

Recibido: 19/04/2015 Aprobado: $24 / 11 / 2015$

1 El artículo fue concebido a raíz de los retos planteados por el proceso de acreditación que el Departamento de Sociología de la Universidad Nacional culminó a finales de 2010. La investigación fue financiada por la Facultad de Ciencias Humanas de la Universidad Nacional.

2 Sociólogo. Doctor en Estudios de Sociedades Latinoamericanas.

3 Sociólogo. 


\title{
Resumen
}

Este artículo recoge y evalúa información, desde la perspectiva de los mercados parciales de trabajo, acerca de los trabajos que desempeñan egresados y egresadas del Departamento de Sociología de la Universidad Nacional de Colombia. Se construyó una cohorte según el año de graduación de los egresados(as) entre 2000 y 2010. En la encuesta y entrevistas se pidió información sobre contratante, actividad desempeñada y condiciones laborales de su primer trabajo y del trabajo actual. Los resultados muestran que la docencia, investigación, consultoría y el trabajo con comunidades son los mercados de trabajo más frecuentes. Los cargos desempeñados en el primer trabajo contemplan una mayor variedad de actividades que los del último, y las condiciones laborales parecen mejorar.

Palabras clave: vivir de la Sociología; sociólogos; mercados parciales de trabajo; condiciones laborales; historial de empleos.

\begin{abstract}
This paper gathers and assesses some information, from the perspective of labor market segmentation, regarding the jobs graduates from the Department of Sociology at Universidad Nacional de Colombia are hired for. A cohort based on the graduation year was built, being the time lapse considered 2000 to 2010. When surveyed and interviewed, graduates were required to tell about their first and current job employer, type of labor and labor conditions. According to the results, graduates are employed mainly in four labor market segments: teaching, research, consultancy, and social service. The positions occupied on the first job involved a wider variety of activities than those in the last one, and labor conditions seem to improve.
\end{abstract}

Keywords: live off sociology; sociologists; labor market segments; labor conditions; employment history.

\section{Resumo}

Este artigo avalia informação dos empregos que desempenham graduados e graduadas do Departamento de Sociologia da Universidad Nacional de Colombia. Construiu-se uma coorte segundo a ano de graduação entre 2000 e 2010. Tanto na enquete como nas entrevistas se solicitou informação sobre contratante, atividade realizada e condições trabalhistas do primeiro emprego e do atual. Os resultados mostram que a docência, a pesquisa, a consultoria e o trabalho com comunidades são os mercados mais frequentes. Os cargos desempenhados no primeiro trabalho contemplam uma maior variedade de atividades que os do último, e as condições trabalhistas parecem melhorar.

Palavras-chave: Viver da sociologia; sociólogos; mercados parciais de trabalho; condições trabalhistas; histórico de empregos.

Este trabajo está bajo la licencia Creative Commons Attribution 3.0

\footnotetext{
¿Cómo citar este artículo? / How to quote this article?

Beltrán, William y Darío Berrío. «Viviendo de la Sociología: egresados(as) de la Universidad Nacional de Colombia y mercados parciales de trabajo». Sociedad y economía, No. 30 (enero - junio de 2016): 121-146.
} 


\section{Introducción}

¿Cuáles son las oportunidades laborales de los egresados de los departamentos y facultades de Sociología de las universidades colombianas? ¿Quiénes son sus principales contratantes? ¿Qué tan estables son sus condiciones laborales? Entre los sociólogos estas preguntas son tan reconocidas por su importancia como por la ausencia de estudios sobre el tema. Así lo afirman quienes se han dado a la tarea de escribir sobre la Sociología en Colombia (Arango 2006; 2007; Segura y Camacho 1999; Restrepo y Restrepo 1997; Cataño 1986). El presente artículo intenta dar respuesta a estas cuestiones. Aborda, por lo tanto, la llamada "cuestión laboral" para egresados(as) de Sociología en Colombia; con base en el estudio de caso de egresados(as) de la Universidad Nacional de Colombia en el período comprendido entre 2000 y 2010.

La ausencia de datos acerca del ejercicio profesional de la Sociología en Colombia ha dejado un vacío sobre las condiciones y oportunidades de quienes viven de la Sociología $a^{4}$. Hasta ahora, salvo por contadas excepciones, las publicaciones sobre el tema se han limitado a señalar este vacío, y las que han lidiado con este basan sus aseveraciones sobre indicios aislados: "No hay estadísticas confiables al respecto, tan solo percepciones y apreciaciones puntuales" (Cubides 1998,12 ). A ciencia cierta, solo sabemos lo que pasa con la disciplina de puertas para dentro de los departamentos, con sus profesores y estudiantes, con las personalidades de la vida académica y con las publicaciones. Aunque no existen estudios que permitan dar cuenta del ejercicio profesional de sociólogos(as) en Colombia, hay iniciativas aisladas que han intentado abordar dicha inquietud desde los departamentos o facultades (Martínez et al. 2007; Páez 1997). El presente trabajo se vale de esta perspectiva para indagar sobre el funcionamiento de los mercados parciales de trabajo en los que participan sociólogos(as) graduados de la Universidad Nacional de Colombia.

Los estudios de caso mencionados coinciden, en general, en ocuparse de tres asuntos: las instituciones contratantes de sociólogos(as), la adecuación (o desfase) entre los programas curriculares y el mundo del trabajo, y los competidores potenciales que enfrentan los sociólogos y sociólogas en el mundo laboral. Entre sus conclusiones se destacan: 1) desde finales de la década de 1980, el Estado, las universidades y las organizaciones no gubernamentales (ONG) han desempeñado un papel preponderante como empleadores de sociólogos(as) (Martínez et al. 2007; Cubides 1998; Cataño 1986). 2) Las competencias que imparten los programas curriculares (conceptualización, teoría, técnicas de investigación, etc.) no contribuyen a encauzar el desempeño profesional de los estudiantes hacia labores específicas. Son aplicables a múltiples ocupaciones sin resultar idóneas para ninguna en particular (Cataño 1986; Gómez 2003); ello evidencia el desfase entre la formación recibida y las demandas del mundo del trabajo. 3) Las personas egresadas de Antropología, Psicología, Trabajo Social y Ciencia Política así como de Sociología compiten por las mismas vacantes. Los potenciales

4 Paráfrasis de la distinción planteada por Weber (2001) entre "vivir de" y "vivir para". Para el presente caso, vive de la Sociología el sociólogo(a) de profesión que trata y logra hacer de ella una fuente duradera de ingresos. 
empleadores no suelen distinguir las diferencias entre unos y otros, haciéndolos fácilmente sustituibles en el mercado laboral (Gómez 2003).

\section{Mercados parciales de trabajo}

El mercado de trabajo general es el conglomerado de mercados parciales de trabajo, definidos con base en las características tanto de empleos (labores para las cuales la fuerza de trabajo es comprada y vendida) como de empleados(as) (categorías de fuerza de trabajo que son compradas y vendidas) que los integran (Sengenberger 1988; Fevre 1992; Pries 1997). Los mercados parciales de trabajo son: "Unidades estructurales del mercado de trabajo general que están delimitadas por determinadas características de los puestos de trabajo o de la mano de obra y dentro de las cuales la asignación, remuneración y cualificación de esta última están sujetas a una normativa especial más o menos institucionalizada" (Sengenberger 1988, 355).

En el caso que nos ocupa, los mercados parciales de trabajo para sociólogos(as) serán definidos a partir de los descriptores que egresados(as) le atribuyen a la actividad laboral que desempeñan, las cualidades y credenciales que les exigen para acceder a las ofertas laborales (experiencia, estudios de posgrado, recomendaciones, etc.), y las condiciones laborales con que cuentan quienes son contratados(as) (salario, tipo de contrato y duración de la vinculación) 5 .

Conocer la situación laboral de la población egresada fue uno de los retos que planteó el proceso de acreditación que atravesó el Departamento de Sociología de la Universidad Nacional de Colombia en 2009; año en el que se implementó un nuevo programa curricular ${ }^{6}$. Para indagar sobre la situación laboral de los egresados(as) y evaluar la incidencia del antiguo programa curricular al respecto se diseñó un cuestionario destinado a egresados(as), que hubiesen finalizado recientemente sus estudios de pregrado. Dicho cuestionario se aplicó durante el segundo semestre de 2013 a 148 egresados(as) del Programa de Sociología de la Universidad Nacional, que se hubiesen graduado entre el 2000 y el 2010; esto significa que fueron consultados $35 \%$ de las personas graduadas en dicho período. El perfil de la muestra se puede describir de la siguiente manera: la edad de los encuestados oscila entre 26 y 40 años; al momento de la encuesta, 31,7\% tenía 7 años o más de haberse graduado (tabla 1); $47,5 \%$ cuenta con títulos de posgrado (tabla 2); la mayoría (51,1\%) se graduó de colegios privados y 4,5\%, de colegios bilingües; la edad de las encuestadas oscila entre 29 y 42 años; al momento de la encuesta, $56 \%$ tenía 7 años o más de haberse graduado (tabla 1); 42,4\% cuenta con títulos de posgrado (tabla 2); la mayoría (64,7\%) se graduó de colegios privados y $8,4 \%$, de colegios bilingües.

5 Por lo tanto, esta perspectiva se aleja de la línea que suelen seguir los trabajos sobre segmentación de mercados en Colombia, donde se privilegia la perspectiva economicista y los segmentos se clasifican como mercados formales e informales (Uribe, Ortiz y García 2007; Posso 2010; Pedraza 2011; Prada 2012).

6 El Departamento de Sociología de la Universidad Nacional es el más antiguo de Colombia. Su cuerpo docente, egresados(as) y programa curricular han sido referentes para el desarrollo de la disciplina en el país. La modificación al programa curricular del Departamento (Consejo Superior Universitario 2007; 2008 -Acuerdo 033 de 2007 y Acuerdo 45 de 2008-), en 2009, implementa el régimen de créditos y hace del inglés la lengua extranjera fundamental, manteniendo la estructura formulada en 1969 (Restrepo y Restrepo 1997). 
Tabla 1. Años de trayectoria de los encuestados

\begin{tabular}{|c|c|r|c|r|r|}
\hline Años & \multicolumn{2}{|c|}{ Eggresadas } & Años & \multicolumn{2}{|c|}{ Egresados } \\
1 a 3 & $6,06 \%$ & 4 & la 3 & $8,54 \%$ & 7 \\
4 a 6 & $37,88 \%$ & 25 & 4 a 6 & $36,59 \%$ & 30 \\
7 a 9 & $36,36 \%$ & 24 & 7 a 9 & $23,17 \%$ & 19 \\
10 a 13 & $19,70 \%$ & 13 & 10 a 13 & $8,54 \%$ & 7 \\
Total egresadas & $\mathbf{1 0 0 , 0 0 \%}$ & $\mathbf{6 6}$ & Total egresados & $\mathbf{1 0 0 , 0 0 \%}$ & $\mathbf{8 2}$ \\
\hline
\end{tabular}

Fuente: elaboración propia.

Tabla 2. Título más alto alcanzado por los encuestados

\begin{tabular}{|l|r|r|l|r|r|}
\multicolumn{1}{|c|}{ Título } & \multicolumn{2}{c|}{ Egresadas } & \multicolumn{2}{c|}{ Título } & \multicolumn{2}{c|}{ Egresados } \\
Profesional & $57,58 \%$ & 38 & Profesional & $52,44 \%$ & 43 \\
Especialista & $9,09 \%$ & 6 & Especialista & $14,63 \%$ & 12 \\
Magíster & $22,73 \%$ & 15 & Magíster & $25,61 \%$ & 21 \\
Con estudios de doctorado & $10,61 \%$ & 7 & Con estudios de doctorado & $7,32 \%$ & 6 \\
Total egresadas & 100,00 & $\mathbf{6 6}$ & Total egresados & $\mathbf{1 0 0 , 0 0}$ & $\mathbf{8 2}$ \\
\hline
\end{tabular}

Fuente: elaboración propia.

El instrumento indagó sobre dos momentos en la trayectoria de las personas encuestadas: el primer empleo tras graduarse del pregrado de sociología y el empleo actual o más reciente. Esta división responde a una perspectiva de trayectoria que intenta dar cuenta de los cambios en la situación laboral a través del tiempo (Blossfeld y Mayer 1988). Ya que la acumulación de credenciales como: títulos de posgrado, recomendaciones (contactos) ${ }^{8}$, experiencia específica certificada y mayor conocimiento del mercado laboral son elementos variables que inciden sobre la situación laboral. Adicionalmente, se realizaron doce entrevistas en profundidad ${ }^{9}$, que permitieron comprender con mayor detalle aspectos relacionados con las actividades laborales desempeñadas y las condiciones de trabajo. Con base en la información recopilada se propone una tipología sobre las alternativas laborales más frecuentemente desempeñadas por los egresados y las egresadas (trabajo con comunidades, docencia, investigación y consultoría) ${ }^{10}$.

El futuro laboral que aguarda a los recién egresados es incierto; a ello contribuye especialmente la vaguedad ocupacional que fomenta la formación impartida en el Departamento de Sociología de la Universidad Nacional de Colombia (Gómez 2009) y el grado de desconocimiento de la carrera en el país (Cataño 2007; 1989; 1986); situación, sin embargo, que no es exclusiva de este departamento (Arango 2006; Gómez 2012). Los egresados y las egresadas del Departamento se demoran más que el promedio nacional de egresados(as) de instituciones de educación superior (IES) en conseguir su primer empleo. Seis meses después

7 No encontramos doctores entre los encuestados(as), sin embargo, 8,7\% de la muestra se encontraba cursando estudios de doctorado en el momento de la encuesta.

8 Desde esta perspectiva, se enfatiza el potencial de los contactos sociales como puente hacia nuevos círculos sociales y nuevas oportunidades laborales (Granovetter 1973).

9 Los nombres de los entrevistados(as) han sido modificados para proteger su intimidad.

10 Las actividades laborales han sido definidas como tipos ideales (Weber 2001, 39-101), pues en sus trayectorias individuales los egresados mezclan diversas actividades. 
de graduados(as), 66,2\% de las personas encuestadas se encontraban empleadas, mientras el promedio nacional para egresados(as) de instituciones de educación superior es aproximadamente $91 \%^{11}$. En cuanto a las actividades desempeñadas, para el primer y segundo empleo fueron seleccionadas las que agrupan a la mayor parte de la población. Estas, además de ser las mismas en uno y otro momento, concentran una porción creciente de la población (tabla 3).

Tabla 3. Principal actividad desempeñada

\begin{tabular}{|l|c|c|}
\multicolumn{1}{|c|}{ Título } & Primer empleo & Ultimo empleo \\
\hline Trabajo con comunidades (talleres) & $23,65 \%$ & $8,78 \%$ \\
Docencia en educación primaria, secundaria y terciaria & $13,51 \%$ & $25,00 \%$ \\
Investigación & $12,84 \%$ & $19,59 \%$ \\
Consultoría & $8,78 \%$ & $16,22 \%$ \\
Total general & $\mathbf{5 8 , 7 8} \%$ & $\mathbf{6 9 , 5 9} \%$ \\
\hline
\end{tabular}

Fuente: elaboración propia.

\section{Trabajo con comunidades}

Según Arango (2007), el trabajo con comunidades figura con mayor frecuencia entre las aspiraciones laborales de egresados(as) con relativamente poco capital social y cultural acumulado. Sin embargo, las actividades relacionadas con este tipo de desempeño laboral vienen siendo objeto de profunda resignificación.

Los relatos de las y los estudiantes muestran cómo algunas jóvenes se ubican en una posición periférica, excluyen la idea de convertirse en académicas o intelectuales y prefieren pensarse por fuera de estos campos, en la acción comunitaria, menos prestigiosa y competitiva (Arango 2007, 195-196).

Entre los sociólogos y las sociólogas, el "trabajo con comunidades" engloba en el imaginario una serie de actividades de campo que implican la interacción directa con grupos: mediación con comunidades, encuestas, talleres, consultas y cooperación en procesos de organizaciones de base, entre otras. "Hay un mercado de ONG bastante grande y muchas veces tiene que ver con irse a las regiones a hacer trabajo de campo" (Guillermo, 4 años trabajando en investigación). Si bien este tipo de trabajo le puede implicar al profesional desplazarse a zonas lejanas (en ocasiones de alto riesgo o con acceso limitado a servicios públicos y de salud ${ }^{12}$, la mayoría de los profesionales en Sociología que han desempeñado "trabajo con comunidades" lo ha hecho en capitales departamentales (84,4\%), particularmente en Bogotá $(66,7 \%)$.

El trabajo con comunidades comprende un conjunto de actividades que trascienden lo que los manuales de metodología definen como "trabajo de campo". Suele implicar actividades de gestión, concertación y organización, orientadas a grupos (étnicos, regionales, laborales, socioeconómicos, etc.) específicos. En ocasiones

11 En 2012, 90,9\% de los recién graduados de IES en Colombia obtuvo su primer empleo antes del séptimo mes, en 2013 la cifra fue 90,6\% (Observatorio Laboral para la Educación 2013).

12 Del total de la muestra de egresados(as), 56,7\% ha aceptado trabajos en zonas de alto riesgo o con acceso limitado a servicios públicos y de salud; 53,5\% lo hizo por interés profesional, $23,8 \%$ por el salario y $9,5 \%$ por interés académico. 
involucra, incluso, tareas burocráticas ${ }^{13}$. De acuerdo con los egresados(as), su formación no les brindó herramientas adecuadas para el desempeño de la mayoría de estas actividades.

De las personas consultadas, 23,6\% desempeñó “trabajo con comunidades" en su primer empleo, mientras en el último empleo el porcentaje de los que se dedican a este tipo de actividades se redujo a 8,8\% (tabla 3). Esto indica que en el desarrollo de sus carreras profesionales, los sociólogos y sociólogas migran con frecuencia hacia otro tipo de actividades. El "trabajo con comunidades" constituye, al parecer, una de las más recurridas puertas de entrada del recién graduado(a) al mundo laboral. En parte, debido a que los empleadores que contratan sociólogos(as) para este tipo de actividades tienen un lugar en su organigrama para recién graduados(as); mano de obra calificada pero barata. Las ONG constituyen el principal empleador de recién graduados(as) (tabla 4); sin embargo, trabajar en ONG es con frecuencia también transitorio en sus trayectorias.

Tabla 4. Trabajo con comunidades: sector y tipos de empresas contratante ${ }^{14}$

\begin{tabular}{|c|c|c|c|c|c|c|}
\hline Sector/Tipo empresa & $\begin{array}{l}\text { Primer } \\
\text { empleo }\end{array}$ & $\begin{array}{c}\mathbf{N}^{\circ} \\
\text { egresados }\end{array}$ & $\begin{array}{c}\mathbf{N}^{\circ} \\
\text { egresadas }\end{array}$ & $\begin{array}{l}\text { Ultimo } \\
\text { empleo }\end{array}$ & $\begin{array}{c}\mathbf{N}^{\circ} \\
\text { egresados }\end{array}$ & $\begin{array}{c}\mathbf{N}^{\circ} \\
\text { egresadas }\end{array}$ \\
\hline Sector privado & $51,43 \%$ & 7 & $\mathbf{1 1}$ & $38,46 \%$ & 2 & 3 \\
\hline Con ánimo de lucro & $5,71 \%$ & 1 & 1 & $7,69 \%$ & 0 & 1 \\
\hline ONG & $45,71 \%$ & 6 & 10 & $23,08 \%$ & 2 & 1 \\
\hline Universidades & $0,00 \%$ & 0 & 0 & $7,69 \%$ & 0 & 1 \\
\hline Sector público & $48,57 \%$ & 9 & 8 & $61,54 \%$ & 3 & 5 \\
\hline Centro de investigación & $2,86 \%$ & 0 & 1 & $0,00 \%$ & 0 & 0 \\
\hline Dependencias nacionales & $11,43 \%$ & 1 & 3 & $38,46 \%$ & 1 & 4 \\
\hline Dependencias regionales & $22,86 \%$ & 6 & 2 & $15,38 \%$ & 1 & 1 \\
\hline Universidades & $11,43 \%$ & 2 & 2 & $7,69 \%$ & 1 & 0 \\
\hline Total general & $100 \%$ & 16 & 19 & $100 \%$ & 5 & 8 \\
\hline
\end{tabular}

Fuente: elaboración propia.

El trabajo con comunidades requiere competencias específicas ${ }^{15}$. En lo relacionado con investigación: recabar y sistematizar información; con acompañamiento y concertación con comunidades: liderazgo, habilidades comunicativas, destrezas relacionadas con la conciliación y la resolución de conflictos, etc. Todo esto debe ser desempeñado en contextos socioculturales específicos.

En esta medida, los aspirantes a estas vacantes deben certificar su idoneidad en dos dimensiones: poseer una formación que les permita llevar a cabo las labores requeridas, y demostrar experiencia en trabajo con comunidades en entornos específicos: "[Para el trabajo con comunidades] están pidiendo experiencia [laboral] específica. Dicen 'necesito un profesional en ciencias sociales que haya trabajado 5 años con

13 Así lo evidencia la multiplicidad de ámbitos de acción sobre el que se mueven las instituciones contratantes. Por ejemplo, la Agencia Colombiana para la Reintegración (ACR) está encargada de: “Coordinar, asesorar y ejecutar la Ruta de Reintegración de las personas desmovilizadas de los grupos armados al margen de la ley así como de diseñar, implementar y evaluar la política de Estado dirigida a la Reintegración de esta población" (ACR s/f).

14 La tabla contempla a quienes ejercieron esta actividad en Colombia, para el primer empleo $94,2 \%$ y para el segundo $84,6 \%$.

15 Entendemos por competencias "la capacidad demostrada de desempeño eficiente en determinados roles y tareas, claramente definidos, estructurados, observados y medidos" (Gómez 2003, 75). 
mujeres negras, desplazadas, etc.' y [a esto le] suman [otros] 10 criterios" (Sofía, 4 años trabajando con comunidades). "En todos los trabajos en los que me he presentado, en todas las entrevistas en las que he pasado, se valora mucho el título, pero sobre todo tu experiencia" (Simón, ll años trabajando con comunidades y 2 años en docencia).

Con el aumento de la experiencia, aumentan el salario y la probabilidad de desempeñar labores distintas al trabajo de campo:

\begin{abstract}
En relación con el salario, hay un relativo aumento según la experiencia acumulada. De proyectos donde mis funciones estaban más vinculadas a la realización de talleres, capacitaciones y trabajo comunitario de base, [pasé] a otro tipo de labores más correspondientes a procesos de aplicación de conocimiento en el cumplimiento directo de las metas y proyectos de la entidad a la cual estoy vinculada (Fernanda, 7 años trabajando con comunidades).
\end{abstract}

Estas condiciones hacen del trabajo con comunidades una alternativa laboral para profesionales que no acreditan estudios de posgrado. Tras la migración hacia otras actividades (tabla 3), el trabajo con comunidades se convierte en un trabajo desempeñado en dependencias nacionales ${ }^{16}$ y ONG (tabla 4) por una mayoría de mujeres sin estudios de posgrado. La proporción de mujeres pasa de $54,3 \%$ a $61,5 \%$ en el último empleo mientras los porcentajes de educación de posgrado se mantienen bajos (con maestría $23,1 \%$, con especialización $15,4 \%$ ); hecho que parece confirmar la afinidad observada por Arango (2007) entre sociólogas y acción comunitaria.

Aunque las credenciales de posgrado no son indispensables para ser contratado para este tipo de actividades, al parecer tienen un efecto importante sobre las condiciones laborales de la contratación: "Si bien en los trabajos que he tenido el posgrado no es un requisito, soy consciente de que la aspiración a una mejor posición profesional depende en parte de obtener el título de posgrado" (Fernanda, 7 años trabajando con comunidades).

Lejos de considerar el trabajo con comunidades y, en particular, el trabajo de campo, como una actividad menor, algunas de las personas entrevistadas lo reivindican por su cercanía con la gente: "Me voy más bien con la gente... con los artesanos a ir a tomar cerveza, a conversar en sus talleres, a jugar, a estar cerca [de ellos], porque para mí es ahí donde está el sentido de la sociología, no en el escritorio" (Horacio, 3 años trabajando en consultoría).

Estas apologías evocan con frecuencia la figura de Orlando Fals Borda como modelo a seguir. Puesto que "desde su propuesta de investigaciónacción-participación expresa el ideal del sociólogo comprometido con el cambio social y político del país" (Arango 2006, 269-270).

16 Dependencias nacionales son aquellas entidades públicas cuya jurisdicción se extiende sobre todo el territorio nacional, por ejemplo, los Ministerios o la Vicepresidencia de la República. Mientras que las dependencias regionales son entidades públicas cuya jurisdicción se limita a una región en particular del territorio nacional, por ejemplo las Gobernaciones, Secretarías Distritales o Corporaciones Regionales. 


\section{Docencia}

Docencia e investigación son actividades estrechamente asociadas con el desempeño profesional de quienes se gradúan del Departamento de Sociología de la Universidad Nacional de Colombia. Tras la reforma curricular de $1969^{17}$, la formación impartida se caracterizó "por un ejercicio de copiosa erudición" que para algunos "formaba docentes más que sociólogos" (Restrepo y Restrepo 1997). Adicionalmente, la docencia es una actividad cuya filiación con la academia parece dotarla de unas condiciones laborales estables y relativamente amables, imaginario que probablemente deriva de la interacción construida entre estudiantes y profesores en el Departamento.

En su libro Pedagogía e Historia, Zuluaga (1999) distingue al docente del maestro:

Pero existe por otra parte, otro sujeto que también enseña y al que se llama docente. Este sujeto de la enseñanza es reconocido como tal, no a partir del método de enseñanza, sino del saber que transmite; él puede ser profesor de matemáticas, profesor de física, profesor de filosofía, profesor de sociología, es decir, su estatuto como docente en la sociedad se le reconoce desde otro saber que no es la pedagogía $(1999,49)$.

El Programa de Sociología de la Universidad Nacional de Colombia no contempla formación en pedagogía $y$, por ende, las personas egresadas que se dedican a la docencia pueden ser definidas, siguiendo a Zuluaga, como transmisoras de sociología. Al parecer el énfasis en las teorías sociológicas clásicas (Durkheim, Marx, Weber) y contemporáneas (Bourdieu, Giddens, Elias, etc.) que ofrece el Departamento se convierte en una ventaja para quienes se desempeñan en la docencia. En primer lugar, porque favorece la apropiación de un repertorio conceptual que puede ser aprendido (incluso simplemente memorizado) y reproducido. Y además, porque esta base teórica representa, al parecer, una herramienta valiosa al cursar estudios de posgrado, uno de los requisitos para ejercer la docencia universitaria: "Cuando hice la maestría me di cuenta de lo importante y bueno que había sido tener una sólida base teórica [Esto] facilitaba mucho entender textos y autores más contemporáneos, que uno nunca había leído [ya que] todos se remiten a los clásicos" (Juliana, 5 años trabajando en docencia y 3 años en investigación).

En términos generales, la labor del sociólogo(a) como docente universitario(a) se desarrolla en dos grandes ámbitos: dentro y fuera de las ciencias sociales. El primer caso tiene lugar en programas como Sociología, Antropología y ciencias afines. En el segundo, el sociólogo cubre el componente correspondiente a las ciencias sociales en programas de ciencias naturales, ingenierías, derecho, artes, etc. (Martínez et al. 2007). Los egresados suelen iniciarse en la docencia en universidades públicas departamentales (Universidad de Manizales, Universidad de

17 En esta reforma "las asignaturas que giraban sobre los aspectos prácticos del desempeño profesional fueron abandonadas y se introdujo un marcado énfasis en las teorías sociológicas. Los métodos y las técnicas de investigación perdieron protagonismo y surgieron materias asociadas con la filosofía de la ciencia y los problemas lógicos y epistemológicos de la investigación social" (Cataño 1986, 41). 
Sucre, Universidad Pedagógica y Tecnológica de Colombia, etc.), instituciones de educación terciara no siempre universitaria (Fundación Universitaria Los Libertadores, Fundación Universitaria Juan de Castellanos, etc.) y en universidades privadas de disímil prestigio y calidad. Su recorrido parece ir de las regiones hacia la capital (la concentración en Bogotá crece de 53,8\% a 62,5\%) y del sector público hacia el privado (la concentración en el sector privado crece de $35 \%$ a 59,4\%). La posesión de títulos de posgrado es fundamental para acceder al desempeño de la docencia en estas instituciones, además de incidir sobre el salario: "Lo mínimo que están pidiendo para [ejercer la] docencia universitaria es maestría y en este momento hasta el doctorado. La maestría es también un factor de incremento salarial, los que estamos con maestría ganamos más que los que tienen una especialización" (Doris, 8 años trabajando en docencia y 3 años en investigación).

En la valoración de los diplomas de posgrado confluyen dos variables, el estado de la oferta (escasez-abundancia) de graduados para el nivel de educación cursado (especialización, maestría, doctorado) y el prestigio de la institución garante de la credencial. A mayor escasez y prestigio más apreciado el título, y viceversa. De tal forma que hay situaciones en las que tener un diploma de posgrado no es suficiente:

\footnotetext{
[En mi trayectoria como docente] la experiencia ha pesado más. Porque los títulos son requisito, pero ahí hay una competencia muy grande. Tienes una maestría pero ¿la tienes nacional o internacional? pero ¿de qué universidad?. La maestría que yo tengo no es mala pero tampoco es [...de] Harvard, entonces [el diploma de posgrado] es requisito pero tampoco ha sido determinante (Juliana, 5 años trabajando en docencia y 3 años en investigación).
}

A pesar de que los requisitos mínimos para ser contratado como docente universitario en Colombia parecen tender a hacerse más exigentes debido a los ajustes que vienen haciendo los programas académicos que buscan la acreditación de alta calidad por parte del gobierno (Consejo Nacional de Acreditación 2013), y a que la competencia aumenta entre aspirantes a las vacantes disponibles, producto de una creciente población de profesionales en Sociología y carreras afines (Cataño 1986; Roberts y Woodward 1981), 48,6\% de las personas encuestadas que dijeron estar dedicadas a la docencia actualmente o haberlo hecho en su último empleo no cuenta con un diploma de maestría. Esto se debe a que los requisitos de contratación no son homogéneos entre las diversas instituciones contratantes, y a la posibilidad con que cuentan los profesionales de recurrir a credenciales alternativas a los títulos de posgrado. De acuerdo a los entrevistados(as), las universidades con requisitos de contratación menos exigentes tienden a convertirse en puertas de entrada al ejercicio de la docencia en la educación terciaria: "Varios amigos que están metidos en la docencia universitaria arrancaron en la Fundación Universitaria Los Libertadores, para lograr el año y medio de experiencia [requerido] para que universidades como la Central los tuvieran en cuenta" (Sofía, 4 años trabajando con comunidades).

Por otro lado, hay casos en los que se recurre a credenciales alternativas al título de posgrado, como la experiencia en un área específica o el capital social: "Una profesora que había sido como mi madrina dentro de la Universidad 
[Nacional] aparece y me hereda unas clases que ella dictaba en la Corporación Universitaria Republicana" (Simón, 11 años trabajando con comunidades y 2 años en docencia). "Me presenté a una convocatoria. La Universidad de Caldas estaba pidiendo docentes como yo había tenido un trabajo con comunidad y había hecho algunos trabajos de investigación, entonces vieron que mi perfil era apropiado para dictar las metodologías de investigación, métodos cuantitativos" (Doris, 8 años trabajando en docencia y 3 años en investigación).

Aunque la docencia no se desempeña exclusivamente en las universidades, es innegable que allí se concentra de manera creciente la actividad docente de los profesionales. El porcentaje de egresados(as) que se dedica a esta actividad en instituciones de educación terciaria aumenta de forma notable entre el primer y último empleo (80\% en el primer empleo y 91,9\% en el último) (tabla 5). En otras palabras, la docencia es una de las actividades hacia la que tienden a migrar los egresados (tabla 3). Es desempeñada mayoritariamente por hombres $(70 \%$ en el primer empleo y $62,2 \%$ en el último). Sin embargo, el porcentaje de egresadas dedicadas a este tipo de actividad parece estar creciendo.

Tabla 5 . Docencia: sector y tipos de empresas contratantes ${ }^{18}$

\begin{tabular}{|c|c|c|c|c|c|c|}
\hline Sector/Tipo empresa & $\begin{array}{l}\text { Primer } \\
\text { empleo }\end{array}$ & \begin{tabular}{|c|}
$\mathbf{N}^{\circ}$ \\
egresados
\end{tabular} & $\begin{array}{c}\mathbf{N}^{\circ} \\
\text { egresadas }\end{array}$ & $\begin{array}{l}\text { Último } \\
\text { empleo }\end{array}$ & $\begin{array}{c}\mathbf{N}^{\circ} \\
\text { egresados }\end{array}$ & $\begin{array}{c}\mathbf{N}^{\circ} \\
\text { egresadas }\end{array}$ \\
\hline Privado & $35,00 \%$ & 4 & 7 & $59,46 \%$ & 12 & 10 \\
\hline Con ánimo de lucro & $15,00 \%$ & 2 & 3 & $5,41 \%$ & 1 & 1 \\
\hline ONG & $5,00 \%$ & 1 & 1 & $2,70 \%$ & 0 & 1 \\
\hline Universidades & $15,00 \%$ & 1 & 3 & $51,35 \%$ & 11 & 8 \\
\hline Público & $65,00 \%$ & 10 & 13 & $40,54 \%$ & 11 & 4 \\
\hline Dependencias regionales & $15,00 \%$ & 2 & 3 & $2,70 \%$ & 1 & 0 \\
\hline Dependencias nacionales & $0,00 \%$ & 0 & 0 & $2,70 \%$ & 0 & 1 \\
\hline Universidades & $50,00 \%$ & 8 & 2 & $35,14 \%$ & 10 & 3 \\
\hline Total general & $100,00 \%$ & 14 & 6 & $100,00 \%$ & 23 & 14 \\
\hline
\end{tabular}

Fuente: elaboración propia.

En general, quienes se dedican a esta actividad desempeñan el cargo de docente (80\% en el primer empleo y $91,8 \%$ en el último); figuras como docente auxiliar o coordinador(a)/encargado(a) son atípicas y tienden a desaparecer tras el primer empleo (pasan de $23 \%$ a $3 \%$ ).

Las condiciones laborales de quienes se dedican a la docencia universitaria son muy diversas. Sin embargo, el sustento contractual de esta diversidad se reduce a una dicotomía, presente en universidades públicas como privadas, sueldo profesional (salary) o salario proletario (wage) (Uricoechea 1995). Quienes reciben sueldo profesional en las universidades públicas son "empleados públicos docentes" (Decreto 1279 de 2002), o "profesores de planta" en las universidades privadas (Pontificia Universidad Javeriana s/f a). Quienes reciben salario proletario en las universidades públicas no son "empleados públicos", y en las universidades privadas son profesores "hora cátedra"19. Este tipo de docente suele

18 La tabla contempla a quienes ejercieron esta actividad en Colombia, para el primer empleo $95 \%$ y para el segundo $94,5 \%$.

19 El nombre dado a cada tipo de docente varía según la universidad, al igual que los pormenores de la remuneración bien sea sueldo profesional o salario proletario. 
tener contratos a corto plazo (por lo general un semestre o un año) y mal remunerados; solo les pagan las horas dictadas y el salario no incluye el tiempo que dedican a la preparación de clases o a la corrección de evaluaciones (Unás 2013).

Además, la remuneración de los docentes, en general, depende de su experiencia, publicaciones y diplomas acumulados (Consejo Superior Universitario 2013-Acuerdo 123 de 2013-; Pontificia Universidad Javeriana s/f b), variables que resultan adversas para profesionales recién graduados(as). Por lo tanto, el desempeño de la actividad docente no siempre coincide con el imaginario de actividad estable y relativamente bien remunerada ${ }^{20}$. De ahí la necesidad que manifiestan algunos profesionales de mantener: "Siempre un pie en la docencia y otro con proyectos [fuera de la academia]. Es que de la docencia nadie vive, o sea de la docencia de cátedra. Entonces hay que mezclar las actividades" (Juliana, 5 años trabajando en docencia y 3 años en investigación).

\title{
4. Investigación
}

El oficio del profesional en Sociología en tanto investigador(a) se caracteriza por la recopilación y análisis de información, que suele ser presentada de manera comprensible para un público específico. "La labor del investigador consiste en tomar un relato cuya coherencia, por lo general es precaria [o nula], y convertirlo para el lector en una secuencia significante y orientada de acontecimientos" (Cubides 1998, 10). En el imaginario de estudiantes y egresados(as), la investigación suele ser exaltada como el oficio ideal para el profesional en sociología. Sin embargo, lo que entienden por investigación no siempre es claro. Según Arango (2007, 194), suele ser "un conjunto de ideas abstractas para la inmensa mayoría", y añade:

\begin{abstract}
Esta exaltación de la investigación es sin duda efecto de los valores dominantes en el departamento, la facultad y la Universidad, pero existe un desfase entre la retórica en torno a la investigación y el lugar que esta ocupa en el plan de estudios, las condiciones reales de la investigación social en la universidad y fuera de esta y sobre todo, las probabilidades efectivas de que las y los egresados de sociología encuentren empleo como investigadores/as (Arango 2007, 194).
\end{abstract}

Aunque las actividades a las que se llama "investigación" son muy diversas, pueden ser clasificadas en dos tipos. Por un lado, participar en algún proyecto de "investigación aplicada", donde la indagación se hace por encargo, con un problema y lapso establecido por el empleador. Por ejemplo, el tipo de investigaciones que hacen por contrato las universidades o los centros de investigación adscritos a ellas. De este tipo de investigación resultan los productos requeridos por la entidad contratante, que rara vez son publicados y que otorgan pocos beneficios simbólicos (o de distinción) a los investigadores involucrados, especialmente a los "asistentes de investigación" o a los "investigadores de apoyo", que

20 Que presenta, por ejemplo, Uricoechea: “Ese sociólogo [que vive de la sociología], menos privilegiado que su contraparte académica, está mucho más sometido a la lucha por la existencia material ferozmente competitiva y característica del mercado ocupacional dentro del cual se mueve" (2001, 21). 
son los cargos usualmente asignados a los recién graduados. "Los trabajos que a mí me salían de investigación eran, por ejemplo, estudios de impacto, hacer diagnósticos, entrevistas, categorizar esas entrevistas" (Doris, 8 años trabajando en docencia y 3 años en investigación).

Las investigaciones realizadas bajo esta modalidad suelen ocuparse de problemas que interesan a entidades muy concretas, y su divulgación rara vez va más allá del informe que recibe la entidad contratante: "Todo trabajo de extensión que se hace en la Universidad [Nacional] debe dejar como producto algo publicable. Pero eso no siempre funciona así, porque en el [afán] de cumplir con los objetivos del proyecto difícilmente queda espacio para investigar con el rigor que una investigación merece" (Diana, 10 años trabajando en investigación).

Entre los contratantes (o clientes) de este tipo de investigaciones se encuentran entidades públicas regionales y nacionales, ONG, universidades y empresas con ánimo de lucro (tabla 6).

Tabla 6 . Investigación: sector y tipos de empresas contratantes ${ }^{21}$

\begin{tabular}{|c|c|c|c|c|c|c|}
\hline Sector/Tipo empresa & $\begin{array}{l}\text { Primer } \\
\text { empleo }\end{array}$ & $\begin{array}{c}\mathbf{N}^{\circ} \\
\text { egresados }\end{array}$ & $\stackrel{\mathbf{N}^{\circ}}{\text { egresadas }}$ & $\begin{array}{l}\text { Último } \\
\text { empleo }\end{array}$ & $\stackrel{\mathbf{N}^{\circ}}{\text { egresados }}$ & $\begin{array}{c}\mathbf{N}^{\circ} \\
\text { egresadas }\end{array}$ \\
\hline Privado & $52,63 \%$ & 7 & 3 & $44,83 \%$ & 7 & 6 \\
\hline Con ánimo de lucro & $5,26 \%$ & 1 & 0 & $13,79 \%$ & 1 & 3 \\
\hline Centro de investigación & $0,00 \%$ & 0 & 0 & $3,45 \%$ & 1 & 0 \\
\hline ONG & $31,58 \%$ & 3 & 3 & $17,24 \%$ & 3 & 2 \\
\hline Universidades & $15,79 \%$ & 3 & 0 & $10,34 \%$ & 2 & 1 \\
\hline Público & $47,37 \%$ & 5 & 4 & $55,17 \%$ & 10 & 6 \\
\hline Centros de investigación & $10,53 \%$ & 1 & 1 & $3,45 \%$ & 1 & 0 \\
\hline Dependencias regionales & $0,00 \%$ & 0 & 0 & $10,34 \%$ & 3 & 0 \\
\hline Dependencias nacionales & $0,00 \%$ & 0 & 0 & $13,79 \%$ & 4 & 0 \\
\hline Universidades & $36,84 \%$ & 4 & 3 & $27,59 \%$ & 2 & 6 \\
\hline Total general & $100,00 \%$ & 12 & 7 & $100,00 \%$ & 17 & 12 \\
\hline
\end{tabular}

Fuente: elaboración propia.

Esta diversidad de contratantes permite suponer una amplia gama de problemas de investigación. Con frecuencia, este tipo de investigaciones hace parte de procesos de asesoría ofrecidos a dichas entidades: "[Si se trata, por ejemplo, de] asesorar al municipio de Pereira para que el gobierno de la ciudad haga una política pública de cultura ciudadana, lo primero que ofrecemos es un estudio de la cultura ciudadana en Pereira" (Diana, 10 años trabajando en investigación).

Las investigaciones realizadas como parte del proceso de asesoría, rara vez son referidas como tal: "Generalmente no se le puede poner ese nombre [investigación] porque a nadie [ajeno a la entidad contratante] le interesa la investigación, generalmente se le pone el nombre de diagnóstico o caracterización" (Diana, 10 años trabajando en investigación).

La "investigación académica" podría definirse por su rigurosidad y erudición en oposición a la "investigación aplicada". Esta aparece como una rareza entre las posibilidades laborales de los egresados: "Investigar y publicar por el

21 La tabla contempla a quienes ejercieron esta actividad en Colombia, para el primer empleo $94,7 \%$ y para el segundo $89,6 \%$. 
conocimiento, eso se vive en la academia pero en el mundo de afuera no" (Simón, 11 años trabajando con comunidades y 2 años en docencia).

[El Centro de Memoria Histórica] es un espacio súper soñado [donde] hay como cuatro [... egresados] de sociología de la [Universidad] Nacional. Pero somos como cuatro entre miles. Es un espacio laboral muy específico y es muy chévere porque cruza muy bien la cosa más académica de [la] investigación: tú tienes que estar trabajando todo el tiempo con hipótesis, con lecturas. Pero por otro lado, estás en un trabajo [remunerado] (Guillermo, 4 años trabajando en investigación).

En este tipo de investigación, el tema y la problemática dependen en buena medida de los intereses del investigador. Sus márgenes de tiempo permiten un proceso de investigación que se acerca, en el imaginario, a los estándares de "rigurosidad académica". Estas investigaciones tienen más posibilidades que las anteriores de ser publicadas y otorgan mayores beneficios simbólicos, a sus autores(as), en el campo de la sociología. Las tesis de posgrado (de doctorado y de maestría) y algunas monografías de pregrado son un ejercicio cercano a este tipo de investigación: "En [investigación académica] solamente he hecho, que yo llame seria [rigurosa], mi tesis de pregrado — de la que tengo un artículo publicado-y la tesis de maestría que está por publicarse" (Diana, 10 años trabajando en investigación).

De ahí que el desempeño de este tipo de investigación se asocie a los estudiantes eternos(as) (Sánchez 2007): "Gente que nunca ha trabajado, que dicen 'yo me gradué, ya voy a terminar la maestría y me voy a quedar haciendo el doctorado'. Y va de beca en beca..., de beca en beca" (Simón, ll años trabajando con comunidades y 2 años en docencia).

La investigación requiere de un nutrido repertorio metodológico y de instrumentos para el procesamiento de la información recogida, aspectos en los que los egresados ubican las flaquezas del programa académico que cursaron. Según la mayoría de las personas entrevistadas, la baja calidad de los cursos sobre metodologías de investigación e instrumentos de procesamiento de información llega a convertirse en un obstáculo para quienes aspiran a desempeñarse como investigadores(as): "Yo hice una maestría en Investigación en Sociología Aplicada. Cuando llegué a la maestría, [en] lo teórico muy bien, pero la parte práctica, que eran clases de SPSS avanzadas y de Atlas Ti, [me sentí] nula. Fue muy difícil ponerse al día con la demás gente que tomaba la maestría" (Juliana, 5 años trabajando en docencia y 3 años en investigación).

De los egresados y las egresadas, $12,8 \%$ dice haber sido contratado(a) para actividades relacionadas con la investigación en su primer empleo, y 19,5\% en el último. Actividades que son desempeñadas mayoritariamente por hombres, aunque con una creciente porción de mujeres $(36,8 \%$ en el primer empleo y $41,3 \%$ en el último). Las investigaciones se desarrollan sobre todo en entornos urbanos ( $88,6 \%$ en capitales departamentales, $81,8 \%$ en Bogotá).

Los cargos de auxiliar o asistente de investigación se registran con frecuencia en el primer empleo (57,8\%), y disminuyen drásticamente en el último (13,7\%). Siendo sustituidos por cargos como investigador(a) (que asciende de $26,3 \%$ a $51,7 \%$ ), y director(a) o coordinador(a) de investigación (que pasa de $0 \%$ a $20,69 \%$ ). Esta transición permite suponer que la experiencia acumulada permite mayor especialización en áreas de investigación determinadas: 
Como asistente de proyectos tenía que encargarme de la parte administrativa, es decir: hacer cartas, hacer las propuestas de contrato del equipo de trabajo, además recoger información, hacer reseñas, hacer borradores de informes. Después pasé a un nivel más de asesora-investigadora, ya no tenía la parte administrativa, me encargaba del componente de espacio público, ahí me fui especializando en el tema (Diana, 10 años trabajando en investigación).

Si bien, la experiencia y los títulos de posgrado acumulados suponen mayores oportunidades laborales para quienes se dedican a la investigación ${ }^{22}$, el perfil del investigador contratado depende con frecuencia de los recursos económicos disponibles para la investigación: "En mi experiencia, [para las investigaciones] se prefiere contratar a una persona que tenga un posgrado a una persona que no lo tenga. Pero también depende de los recursos que haya, porque si hay recursos muy reducidos se prefiere contratar a una persona primípara [recién graduada]" (Diana, 10 años trabajando en investigación).

\section{Consultoría}

El consultor es un experto(a) o especialista en una determinada materia o problema, que ofrece su dictamen profesional a consultantes (por lo general legos) con intereses en dicho tema. La consultoría aparece tímidamente entre las ocupaciones asociadas al desempeño laboral de los sociólogos (Arango 2007; Gómez 2009). Escasamente aparece entre las expectativas laborales de los estudiantes de sociología de la Universidad Nacional: "Yo veía que un sociólogo podía desempeñarse principalmente en el ámbito de la docencia, sobre todo en docencia universitaria, y obviamente en investigación, y yo tenía la idea, no sé si fue porque mi mamá alguna vez me lo dijo, que los sociólogos [también] hacían consultoría" (Doris, 8 años trabajando en docencia y 3 años en investigación).

Preguntas específicas, cuya formulación corresponde al empleador, orientan el quehacer del consultor(a). En tanto experto(a), el criterio y, por ende, las opiniones del consultor son valoradas en espacios laborales muy específicos. Las herramientas teóricas que provee el programa de Sociología de la Universidad Nacional, les permiten a los egresados consolidar un marco analítico que suele ser útil a la hora de estructurar criterios y opiniones:

La estructura de análisis que te da la Universidad [Nacional] a lo largo de los semestres y el programa de estudio, ayuda a que crees tu propio discurso, tus propias herramientas para hacer los análisis correspondientes a las situaciones sociales en general y efectivamente eso es lo que en mi caso interesa. La capacidad de poder opinar sobre algo con fundamento (Tomás, 3 años trabajando en consultoría).

El campo de experticia del consultor(a) circunscribe su ámbito de acción a ciertos temas. Estos temas tienen momentos de auge y declive lo cual incide sobre el tipo de experticia demandada. Se identificaron dos tipos de estrategia frente a esta situación: quienes se concentran en un solo tema y quienes procuran cubrir varios.

22 Entre quienes se desempeñaron en investigación en su último empleo, 44,8\% tenía maestría y $20,6 \%$, especialización. 


\begin{abstract}
Las personas que se concentran [en un solo tema] se vuelven grandes expertos en unos temas que pueden pasar o no de moda. Es más difícil adaptarse [al cambio en el tipo de experticia demandada] para alguien que ha hecho un doctorado [o se ha especializado en un campo muy específico, por ejemplo] en conflicto armado, en víctimas o en medio ambiente (Horacio, 3 años trabajando en consultoría).
\end{abstract}

En la medida en que un experto necesita actualizarse constantemente, y que los fenómenos y problemas sociales están en constante evolución, la consultoría y la investigación suelen ir de la mano. Con frecuencia el consultor se presenta también como investigador. Por otro lado, ser reconocido como experto(a) en un tema suele abrirle al consultor las puertas de la docencia universitaria ${ }^{23}$.

Por su parte, los consultores que se ocupan de varios temas recurren a la diversificación para adaptarse a las fluctuaciones en el tipo de experticia demandada. Esta estrategia privilegia la versatilidad sobre la superespecialización. "Hay un [consultor que] cuando yo lo conocí trabajaba con indígenas. Venía de trabajar con negros. Entonces me puse a revisar y él ha hecho una espiral, otra vez indígenas, negros, campesinos, indígenas, negros, campesinos, va adaptando su lógica de consultoría a los distintos temas. Sin tomar un tema de forma monolítica" (Horacio, 3 años trabajando en consultoría).

En esta estrategia, la adaptabilidad constituye un atributo primordial. Al respecto, los estudios de posgrado desempeñan un papel definitorio e implican mayores oportunidades laborales y mejores condiciones salariales: "La intención es hacer una maestría en economía, porque el área de la consultoría en que me desempeño se enfoca mucho en el desarrollo económico de los países, entonces hacer la maestría en economía me daría más herramientas para darme a conocer como consultor" (Tomás, 3 años trabajando en consultoría). "Creo que eso es lo que me lleva a pensar a que este próximo año quiero hacer una maestría en metodologías de investigación social porque eso se adapta [a diversos espacios laborales]" (Horacio, 3 años trabajando en consultoría).

Según las respuestas de las entrevistas, en este mercado parcial de trabajo los estudios de posgrado son más valorados que la experiencia por los empleadores ${ }^{24}$. Sin embargo, de los 24 encuestados(as) que se dedican a la consultoría en su último empleo, el porcentaje de los que cuentan con estudios de posgrado es bajo ( $75 \%$ no tiene estudios de maestría y 83,33\% no tiene estudios de especialización). Esto evidencia que tanto la experiencia como el capital social también son credenciales válidas en este mercado parcial de trabajo.

Entre los egresados y egresadas, la consultoría es desempeñada por una creciente mayoría de hombres $(53,8 \%$ en el primer empleo y $62,5 \%$ en el último), en entornos predominantemente urbanos ( $91,6 \%$ en capitales departamentales, $83,3 \%$ en Bogotá). Las ONG son los principales contratantes durante el primer empleo, y las dependencias públicas, tanto nacionales como regionales, en el último (tabla 7). Hay una

23 Por ejemplo, el Centro de Estudios Sociales "realiza actividades académicas mediante el trabajo de docentes adscritos/as que llevan a cabo proyectos en su seno. Al mismo tiempo, su trabajo de extensión como consultores y asesores de entidades estatales les permite influir en la toma de decisiones sobre las políticas públicas y sociales concordantes con sus investigaciones y estudios" (Centro de Estudios Sociales s/f).

24 "Pesa más la academia, tener más cartones, claro eso acredita más. Le creen más, es muy difícil que por la experiencia le crean" (Horacio, 3 años trabajando en consultoría). 
notable variedad de instituciones en el sector público y privado que contratan consultores $^{25}$; no obstante, esto no necesariamente implica consultas a propósito de temas diametralmente distintos.

Tabla 7. Consultoría: sector y tipos de empresas contratantes ${ }^{26}$

\begin{tabular}{|l|r|r|r|r|c|c|}
\hline Sector/lipo empresa & $\begin{array}{r}\text { Primer } \\
\text { empleo }\end{array}$ & $\begin{array}{c}\mathbf{N}^{\circ} \\
\text { egresados }\end{array}$ & $\begin{array}{r}\mathbf{N}^{\circ} \\
\text { egresadas }\end{array}$ & $\begin{array}{c}\text { Ultimo } \\
\text { empleo }\end{array}$ & $\begin{array}{c}\mathbf{N}^{\circ} \\
\text { egresados }\end{array}$ & $\begin{array}{c}\mathbf{N}^{\circ} \\
\text { egresadas }\end{array}$ \\
\hline Privado & $\mathbf{5 3 , 8 5 \%}$ & $\mathbf{5}$ & $\mathbf{2}$ & $\mathbf{2 9 , 1 7 \%}$ & $\mathbf{5}$ & $\mathbf{2}$ \\
Con ánimo de lucro & $7,69 \%$ & 1 & 0 & $16,67 \%$ & 3 & 1 \\
ONG & $46,15 \%$ & 4 & 2 & $8,33 \%$ & 2 & 0 \\
Público & $\mathbf{4 6 , 1 5 \%}$ & $\mathbf{2}$ & $\mathbf{4}$ & $\mathbf{7 0 , 8 3} \%$ & $\mathbf{1 0}$ & $\mathbf{7}$ \\
Centros de investigación & $0,00 \%$ & 0 & 0 & $4,17 \%$ & 1 & 0 \\
Dependencias nacionales & $15,38 \%$ & 1 & 1 & $41,67 \%$ & 5 & 5 \\
Dependencias regionales & $7,69 \%$ & 1 & 0 & $25,00 \%$ & 4 & 2 \\
Universidades & $\mathbf{2 3 , 0 8 \%}$ & 0 & 3 & $0,00 \%$ & 0 & 0 \\
Total general & $\mathbf{1 0 0 , 0 0 \%}$ & $\mathbf{7}$ & $\mathbf{6}$ & $\mathbf{1 0 0 , 0 0 \%}$ & $\mathbf{1 5}$ & $\mathbf{9}$ \\
\hline
\end{tabular}

Fuente: elaboración propia.

La distinción entre asesor(a) y consultor(a) no es del todo clara. Sin embargo, algunos de los entrevistados intentaron precisarla: "Un asesor tiene una permanencia mayor en el tiempo, conoce de forma amplia y profunda varios temas (normalmente asesora desde la distancia), un consultor corresponde a tareas puntuales y concretas, generalmente se contacta con las comunidades" (Horacio, 3 años trabajando en consultoría).

Aunque la diferencia pueda inducir a equívocos o sea exclusivamente nominal y no esté basada en las labores efectivamente desempeñadas por los profesionales, el porcentaje de egresados(as) contratados(as) como consultores(as) tiende a disminuir entre el primer y el último empleo $30,7 \%$ en el primer empleo, $16,6 \%$ en el último) mientras que el de contratados(as) como asesores(as) aumenta ( $7,6 \%$ en el primero, 20,8\% en el último).

\section{Condiciones laborales}

Las condiciones laborales de los egresados, consideradas en términos de salario, tipo de contrato y duración de la vinculación, parecen ser —-salvo ciertas excepciones- similares en los distintos tipos de actividades analizadas. El salario depende de la variación de múltiples elementos, entre los que sobresalen: la acreditación de experiencia laboral y de estudios de posgrado, así como las políticas internas de la empresa contratante. Ser contratado por una empresa es el resultado de una negociación, en ocasiones tácita, donde las partes acuerdan ciertas condiciones (Fevre 1992).

El margen de negociación en que se mueven las empresas y entidades, con respecto al salario, depende de sus políticas internas, es decir, del escalafón según el que se rijan: "El salario es una constante negociación, depende de la institución a la que estés

25 Fundación Guayacanal, Megaoil, USAid, Asociación de Familiares de Detenidos y Desaparecidos, Aecom, Maloka Centro Interactivo, entre otras.

26 La tabla contempla a quienes ejercieron esta actividad en Colombia, para el primer empleo $100 \%$ y para el segundo $95,8 \%$. 
ofreciendo tus servicios. Colciencias [por ejemplo] tiene estipulados unos rangos de salario según tus años de experiencia, según tu nivel de formación, entonces ahí no hay mucho que negociar" (Tomás, 3 años trabajando en consultoría). "Muy seguramente un sociólogo o una socióloga [que] solo [cuente] con pregrado, que trabaje en [el sector de los] hidrocarburos, gana más que yo [magíster en ciencias sociales]" (Teresa, 5 años trabajando en docencia).

Entre el primer y el último empleo se observa un aumento salarial generalizado (el porcentaje que gana más de 3 salarios mínimos pasa de $24,8 \%$ a $77,7 \%$ ) (tablas 8 y 9). Esto se explica por la constante acumulación de experiencia laboral y capital social, y no tanto por la acreditación de títulos de posgrado $32,4 \%$ de los consultados puede acreditar maestría, $16,9 \%$ especialización y $4,7 \%$ ambas).

La disponibilidad de los recursos necesarios para cursar exitosamente un programa académico universitario varía según el origen social de la persona y depende, en buena medida, del capital (económico y cultural) heredado (Bourdieu y Passeron 2009; Arango, Quintero y Mendoza 2004). Para el caso de los egresados que aspiran a completar un programa de posgrado, los principales obstáculos son el costo de la educación y la disponibilidad de tiempo. Con respecto al primer aspecto una entrevistada comenta: "La realización de un posgrado ha sido hasta el momento imposible, por la falta de un ingreso constante que me permita pagar los gastos que conlleva, aunque me he presentado a las pruebas y he tenido la oportunidad de complementar mi pregrado, los costos me han limitado para hacerlo" (Gabriela, 8 años trabajando con comunidades).

Tabla 8. Egresados: tipo de contrato y rango salarial egresados (SM) ${ }^{27}$

\begin{tabular}{|c|c|c|c|c|c|c|c|c|c|c|c|}
\hline & \multicolumn{6}{|c|}{ Primer empleo egresados } & \multicolumn{5}{|c|}{ Último empleo egresados } \\
\hline & $\begin{array}{l}\text { Menor } \\
a 1 \text { (SM) }\end{array}$ & $\begin{array}{l}1 a_{3} \\
(\mathrm{SM})\end{array}$ & $\begin{array}{l}4 a 6 \\
(S M)\end{array}$ & $\begin{array}{l}7 a 9 \\
(\mathrm{SM})\end{array}$ & $\begin{array}{l}100 \\
\text { más } \\
\text { (SM) }\end{array}$ & $\begin{array}{c}\text { Total } \\
\text { general }\end{array}$ & $\begin{array}{l}1 a 3 \\
\text { (SM) }\end{array}$ & $\begin{array}{l}4 a 6 \\
(S M)\end{array}$ & $\begin{array}{l}7 a 9 \\
(S M)\end{array}$ & $\begin{array}{l}100 \\
\text { más } \\
\text { (SM) }\end{array}$ & $\begin{array}{c}\text { Total } \\
\text { general }\end{array}$ \\
\hline Término fijo & $0,00 \%$ & $15,85 \%$ & $6,10 \%$ & $0,00 \%$ & $0,00 \%$ & $21,95 \%$ & $6,49 \%$ & $20,78 \%$ & $5,19 \%$ & $0,00 \%$ & $32,47 \%$ \\
\hline $\begin{array}{l}\text { Término } \\
\text { indefinido }\end{array}$ & $0,00 \%$ & $6,10 \%$ & $2,44 \%$ & $0,00 \%$ & $2,44 \%$ & $10,98 \%$ & $2,60 \%$ & $10,39 \%$ & $3,90 \%$ & $1,30 \%$ & $18,18 \%$ \\
\hline $\begin{array}{l}\text { Prestación de } \\
\text { servicios }\end{array}$ & $2,44 \%$ & $41,46 \%$ & $17,07 \%$ & $1,22 \%$ & $0,00 \%$ & $62,20 \%$ & $11,69 \%$ & $16,88 \%$ & $14,29 \%$ & $3,90 \%$ & $46,75 \%$ \\
\hline $\begin{array}{l}\text { Docente hora } \\
\text { cátedra }\end{array}$ & $0,00 \%$ & $1,22 \%$ & $0,00 \%$ & $0,00 \%$ & $0,00 \%$ & $1,22 \%$ & $0,00 \%$ & $0,00 \%$ & $0,00 \%$ & $0,00 \%$ & $0,00 \%$ \\
\hline Sin contrato & $1,22 \%$ & $1,22 \%$ & $0,00 \%$ & $0,00 \%$ & $0,00 \%$ & $2,44 \%$ & $0,00 \%$ & $1,30 \%$ & $0,00 \%$ & $0,00 \%$ & $1,30 \%$ \\
\hline Becario & $0,00 \%$ & $0,00 \%$ & $0,00 \%$ & $0,00 \%$ & $0,00 \%$ & $0,00 \%$ & $1,30 \%$ & $0,00 \%$ & $0,00 \%$ & $0,00 \%$ & $1,30 \%$ \\
\hline Voluntariado & $0,00 \%$ & $1,22 \%$ & $0,00 \%$ & $0,00 \%$ & $0,00 \%$ & $1,22 \%$ & $0,00 \%$ & $0,00 \%$ & $0,00 \%$ & $0,00 \%$ & $0,00 \%$ \\
\hline $\begin{array}{l}\text { Total } \\
\text { egresados }\end{array}$ & $3,66 \%$ & $67,07 \%$ & $25,61 \%$ & $1,22 \%$ & $2,44 \%$ & $100,00 \%$ & $22,08 \%$ & $49,35 \%$ & $23,38 \%$ & $5,19 \%$ & $100,00 \%$ \\
\hline Total general & $4,70 \%$ & $70,47 \%$ & $21,48 \%$ & $2,01 \%$ & $1,34 \%$ & $100,00 \%$ & $22,30 \%$ & $52,70 \%$ & $21,62 \%$ & $3,38 \%$ & $100,00 \%$ \\
\hline
\end{tabular}

Fuente: elaboración propia.

27 Las columnas de la tabla 8 y 9 toman como unidad el salario mínimo vigente (SM) en Colombia en 2013, equivalente a 589.00opesos colombianos (Decreto 2738 de 2012). 
Tabla 9. Egresadas: tipo de contrato y rango salarial egresadas (SM)

\begin{tabular}{|c|c|c|c|c|c|c|c|c|c|c|c|}
\hline & \multicolumn{6}{|c|}{ Primer empleo egresadas } & \multicolumn{5}{|c|}{ Último empleo egresadas } \\
\hline & $\begin{array}{l}\text { Menor } \\
a \perp \text { (SM) }\end{array}$ & $\begin{array}{l}1 \text { a } 3 \\
\text { (SM) }\end{array}$ & $\begin{array}{l}4 a 6 \\
(S M)\end{array}$ & $\begin{array}{l}7 a 9 \\
\text { (SM) }\end{array}$ & $\begin{array}{l}100 \\
\text { más } \\
\text { (SM) }\end{array}$ & $\begin{array}{c}\text { Total } \\
\text { general }\end{array}$ & $\begin{array}{l}\operatorname{la} 3 \\
(S M)\end{array}$ & $\begin{array}{l}4 a 6 \\
(\mathrm{SM})\end{array}$ & $\begin{array}{l}7 a 9 \\
(\mathrm{SM})\end{array}$ & $\begin{array}{l}100 \\
\text { más } \\
\text { (SM) }\end{array}$ & $\begin{array}{c}\text { Total } \\
\text { general }\end{array}$ \\
\hline Término fijo & $0,00 \%$ & $9,09 \%$ & $4,55 \%$ & $0,00 \%$ & $0,00 \%$ & $13,64 \%$ & $10,00 \%$ & $20,00 \%$ & $6,67 \%$ & $1,67 \%$ & $38,33 \%$ \\
\hline $\begin{array}{l}\text { Término } \\
\text { indefinido }\end{array}$ & $0,00 \%$ & $3,03 \%$ & $4,55 \%$ & $3,03 \%$ & $0,00 \%$ & $10,61 \%$ & $6,67 \%$ & $10,00 \%$ & $3,33 \%$ & $0,00 \%$ & $20,00 \%$ \\
\hline $\begin{array}{l}\text { Prestación de } \\
\text { servicios }\end{array}$ & $6,06 \%$ & $60,61 \%$ & $6,06 \%$ & $0,00 \%$ & $0,00 \%$ & $72,73 \%$ & $6,67 \%$ & $25,00 \%$ & $10,00 \%$ & $0,00 \%$ & $41,67 \%$ \\
\hline Subcontrato & $0,00 \%$ & $0,00 \%$ & $1,52 \%$ & $0,00 \%$ & $0,00 \%$ & $1,52 \%$ & $0,00 \%$ & $0,00 \%$ & $0,00 \%$ & $0,00 \%$ & $0,00 \%$ \\
\hline Voluntariado & $0,00 \%$ & $1,52 \%$ & $0,00 \%$ & $0,00 \%$ & $0,00 \%$ & $1,52 \%$ & $0,00 \%$ & $0,00 \%$ & $0,00 \%$ & $0,00 \%$ & $0,00 \%$ \\
\hline $\begin{array}{l}\text { Total } \\
\text { egresadas }\end{array}$ & $6,06 \%$ & $74,24 \%$ & $16,67 \%$ & $3,03 \%$ & $0,00 \%$ & $100,00 \%$ & $23,33 \%$ & $55,00 \%$ & $20,00 \%$ & $1,67 \%$ & $100,00 \%$ \\
\hline Total general & $4,70 \%$ & $70,47 \%$ & $21,48 \%$ & $2,01 \%$ & $1,34 \%$ & $100,00 \%$ & $22,30 \%$ & $52,70 \%$ & $21,62 \%$ & $3,38 \%$ & $100,00 \%$ \\
\hline
\end{tabular}

Fuente: elaboración propia.

Sobre el tiempo disponible, cabe señalar que la mayoría de quienes han iniciado estudios de posgrado no han contado con beca. Esto les ha obligado a trabajar y estudiar simultáneamente, lo que suele implicar un menor rendimiento en ambas áreas $(53,1 \%$ trabajó para costear sus estudios, $18 \%$ estuvo becado, $15,6 \%$ pidió crédito y $13,2 \%$ recibió apoyo familiar). Adicionalmente, una deficiente formación en lenguas extranjeras limita las posibilidades en cuanto a países, universidades, programas y becas para cursar estudios de posgrado: "La mayoría de las becas, por ejemplo las Fulbright, algunas becas en Alemania -que son muy buenas, del DAAD - o en Suecia, piden inglés. Entonces yo decía: 'tengo todo, el promedio, la experiencia y todo pero lo que siempre me detiene es el inglés"'28 (Doris, 8 años trabajando en docencia y 3 años en investigación).

El formulario empleado para recoger los datos suponía que cada egresado(a) se desempeñaba en un solo empleo. Sin embargo, la indagación reveló lo contrario; la mayoría de los egresados cumplen de manera simultánea con diversos compromisos contractuales ${ }^{29}$. De ahí que los datos sean, probablemente, una subrrepresentación de los ingresos reales de egresados(as) (tablas 8 y 9).

La experiencia laboral aporta a egresados y egresadas elementos de juicio para prever la cantidad de tiempo y esfuerzo requerido para la realización de ciertos productos (usualmente informes) exigidos por un contratante; esto resulta muy útil al aceptar varias contrataciones simultáneamente. Es común que deban enfrentar temporadas en las que se ven abocados a atender dos o tres

28 Si bien 44,1\% de la muestra afirma dominar un segundo idioma, 90,9\% de los programas de posgrado iniciados (especialización, maestría y doctorado) son ofrecidos por universidades en países hispanoparlantes.

29 "Siempre trabajo como en dos o en tres cosas, o algo así, trabajos pequeños al [mismo] tiempo" (Teresa, 5 años trabajando en docencia). "[Enfrenté] la necesidad de estar [aceptando contratos] paralelos. A veces uno se revienta, pero si me sale un [contrato por] tres meses no más pues ya me saldrá algo después. Y paralelamente [acepto] algo por 6 meses" (Diana, 10 años trabajando en investigación). 
compromisos laborales con distintos contratantes, para enseguida enfrentar períodos en los que no tienen empleo. Esta situación está relacionada con el predominio de las contrataciones por prestación de servicios (tablas 8 y 9).

De acuerdo con la ley colombiana, el contrato por prestación de servicios no es un contrato laboral ${ }^{30}$, pues no estipula subordinación entre empleador (contratante) y empleado (contratista). En otras palabras, el contratante no puede exigirle al contratista el cumplimiento de órdenes específicas o "imponerle reglamentos" (Artículo 23, CST). Por lo tanto, el contratista es libre de decidir las condiciones (de lugar y horario, por ejemplo) en que lleva a cabo las labores encomendadas por el contratante (productos). Incluso, es libre de prestar sus servicios a diferentes contratantes de forma simultánea, siempre y cuando cumpla con las condiciones de entrega de los productos pactados (forma, contenido, fecha, etc.) ${ }^{31}$. Para quienes se desempeñan como docentes universitarios, el equivalente al contrato por prestación de servicios es la figura del profesor(a) por hora-cátedra ${ }^{32}$.

El contrato por prestación de servicios implica, además, una disminución en el salario neto recibido, pues transfiere al contratista el total de las contribuciones a pensión, salud y cesantías (Artículo 128 y 249 CST): "Para empezar a trabajar tienes que tener una base de dinero, no puedes firmar el contrato si no has pagado salud y pensión. El año pasado el contrato era por tres millones. Pues es mentira que son tres millones porque de esos tres millones se te van seiscientos mil pesos pagando salud y pensión" (Simón, 11 años trabajando con comunidades y 2 años en docencia).

Por otro lado, el contrato por prestación de servicios suele implicar otras desventajas para el contratista. Por ejemplo, con frecuencia los productos pactados requieren una inversión en tiempo que supera la duración del contrato. En otras palabras, aunque los contratos estipulan una duración específica, el trabajo requerido bien puede extenderse fuera de estos márgenes sin que ello suponga necesariamente pagos adicionales para el contratista:

\footnotetext{
Es algo que tienes que asumir en la vida laboral de las órdenes [contratos] de prestación de servicio. Si uno dice: 'voy a ejercer el derecho a que yo solo trabajo dentro del marco [temporal] en el que está mi contrato', te van a decir: 'es que usted trabaja por productos y hasta que ese producto no esté listo pues usted no ha terminado su trabajo' (Diana, 10 años trabajando en investigación).
}

En el lapso transcurrido entre el proceso de contratación y la firma del contrato, el contratista no recibe dinero, sin embargo, durante este tiempo el

30 Contrato de trabajo es aquel por el cual una persona natural se obliga a prestar un servicio personal a otra persona, natural o jurídica, bajo la continuada dependencia o subordinación de la segunda y mediante remuneración (República de Colombia 1950, Art. 22. CST). El contrato por prestación de servicios es una forma de arrendamiento de servicios inmateriales (República de Colombia 1887. Código Civil).

31 Se observaron algunos contratos por prestación de servicios que llegan a restringir esta libertad del contratista por medio de clausulas especiales: "Y todo lo otro' dicen los contratos, 'y todo lo que se requiera para la ejecución del proyecto'. Entonces tú terminas cumpliendo horario, trabajando de día, de noche, te llaman a la hora que quiera" (Simón, ll años trabajando con comunidades y 2 años en docencia).

32 Este tipo de vinculación supone para los docentes una remuneración a destajo por las horas de clase dictadas (Unás 2013; Uricoechea 1995). 
contratante ya espera avances y dedicación de tiempo por parte del contratista (esta situación parece presentarse con mayor frecuencia en entidades públicas): "pasan dos meses haciéndote el contrato mientras que tú ya tienes que estar trabajando" (Simón, 11 años trabajando con comunidades y 2 años en docencia).

A diferencia del salario o el tipo de contrato (tablas 8 y 9), la duración de los contratos no parece presentar transiciones notables a lo largo de las trayectorias laborales. Si bien los contratos se hacen ligeramente más largos, la inmensa mayoría no supera el año de duración. En el primer trabajo, 58,7\% de las vinculaciones duraron seis meses o menos y $34,1 \%$ entre siete y doce meses; en el último contrato $46,8 \%$ se pactaron a lapsos de seis meses o menos y $45,9 \%$ entre siete y doce meses. "En mis once años de vida laboral, siempre he trabajo por órdenes [contratos] de prestación de servicios y, como te contaba al principio, nunca he tenido un contrato mayor a seis meses" (Diana, 10 años trabajando en investigación). "Cada vez los tiempos de duración de los contratos son más cortos para [entregar] más cosas" (Gabriela, 8 años trabajando con comunidades).

La brevedad de las vinculaciones hace del desempleo y otros períodos sin ingresos, eventualidades recurrentes en la experiencia laboral. Frente a esta situación, los profesionales buscan múltiples fuentes de ingresos y aprenden a administrar sus recursos considerando los meses en que no perciben ingreso alguno: “Trabajas cinco, seis meses, que [es la duración de] los contratos generalmente, y en esos meses tienes que haber generado un colchón para poder soportar los meses que quedas sin contrato. Así es cómo sobrevive la gente [que depende de contratos de prestación de servicios]" (Simón, 11 años trabajando con comunidades y 2 años en docencia).

Este tipo de situaciones no facilita consolidar proyectos personales de largo plazo: "Yo decía: ‘Por qué la plata no [me] alcanza? ¿Por qué tengo tantas deudas con la tarjeta [de crédito]?' Y claro, el ingreso que recibía por seis meses lo tenía que alargar. Es un poco frustrante en términos de la capacidad de endeudamiento, de la posibilidad de ahorrar" (Diana, 10 años trabajando en investigación). "Yo tengo un amigo sociólogo que se ganaba cinco millones [de pesos mensuales] de dos proyectos, pero como eran [contratos] como a seis meses no le arrendaban [un inmueble]" (Sofía, 4 años trabajando con comunidades).

De las contrataciones por prestación de servicios, los entrevistados rescatan el aprendizaje de habilidades relacionadas con la versatilidad y la racionalización, tanto del tiempo como de los ingresos, así como la autonomía que permiten: "Trabajar así, por prestación de servicios, tiene de jarto el tema económico, pero tiene de bueno que uno puede hacer varias cosas a la vez, que uno aprende a manejar su tiempo y que uno no tiene necesariamente que estar de lleno en un trabajo todo el día. Puede hacer uso de su tiempo de una forma más libre" (Diana, 10 años trabajando en investigación).

Si bien las contrataciones son breves, la posibilidad de tener múltiples trabajos permite aumentar los ingresos percibidos con base en la formula: "a mayor tiempo libre, menos dinero recibido" (Unás 2013). De ahí que procurarse ingresos altos pueda exigir un ritmo laboral frenético y agotador.

Estoy cansado de estar haciendo tanta cosa. Entonces [me digo], voy a dedicarme solo a esto: trabajo de ocho de la mañana a cinco de la tarde, y dedico tiempo libre 
a mí, a descansar y a dormir, y a leer literatura y no a leer cosas de trabajo. Este año empiezo a hacer eso. Gano la mitad de lo que ganaba el año pasado pero estoy bien, me siento tranquilo (Horacio, 3 años trabajando en consultoría).

La incertidumbre, inestabilidad y angustia propias de las contrataciones por prestación de servicios contrastan con la estabilidad y seguridad que pueden brindar los contratos laborales indefinidos o de renovación automática: "La estabilidad que te da ganar un salario mensual es una tranquilidad enorme uno ya asume otras cosas: el adquirir una vivienda, tener una familia" (Isabela, 7 años trabajando como docente de planta).

Aunque el contrato por prestación de servicios es predominante a lo largo de la trayectoria laboral de las personas encuestadas, los contratos laborales (a término fijo e indefinido) son mayoritarios en el último empleo ${ }^{33}$ (tablas 8 y 9). El aumento de este tipo de contratos no responde a la adquisición de credenciales de posgrado. La mayoría de los vinculados por este tipo de contratos no tiene posgrado $(85,1 \%$ no tiene especialización y $62,1 \%$ no cuenta con diploma de maestría). La adquisición de credenciales de otra índole, como capital social y experiencia, así como la constante búsqueda de condiciones laborales más estables puede ayudar a explicar la transición observada en los salarios y el tipo de contratos.

\section{A modo de conclusión}

El desempeño laboral de los egresados y las egresadas se concentra en cuatro mercados laborales parciales: el de la investigación, el de la docencia, el de la consultoría y el del trabajo con comunidades. Aunque todos son congruentes con el perfil de egreso del Departamento de Sociología de la Universidad Nacional (Gómez 2009), las actividades que desempeñan los egresados revelan un desfase entre las expectativas de los estudiantes y las posibilidades objetivas que ofrecen los mercados parciales de trabajo.

Entre el primer empleo y el más reciente, la mayoría de egresados(as) cambia de mercado parcial de trabajo, de contratante y de cargo; esta migración tiene tres rasgos principales: se tiende a abandonar el trabajo con comunidades, las labores desempeñadas se hacen más específicas y, salvo en el caso de la docencia, se tiende a abandonar el sector privado. A propósito de esta migración y sus características, se obtuvieron las siguientes observaciones: en primer lugar, la migración coincide con un mejoramiento de las condiciones laborales en cuanto a salario y tipo de contrato. En segundo lugar, los cargos ocupados por los profesionales durante el primer empleo tenían denominaciones genéricas (asistente, gestor, promotor, auxiliar) e implicaban el desempeño de una amplia gama de labores diferentes. En el empleo más reciente, son reemplazados por cargos con denominaciones más específicas (investigador, consultor, docente) donde la gama de labores se reduce. En tercer lugar, en el último empleo aumenta la

33 Durante el primer empleo solo las dependencias regionales y entidades con ánimo de lucro vincularon egresados por medio de contratos laborales. En el último empleo, universidades, entidades con ánimo de lucro, dependencias nacionales y regionales recurrieron a este tipo de vinculación. 
variedad de empleadores. De ahí que los cargos desempeñados por egresados(as), otrora concentrados en universidades públicas y ONG, se redistribuyan a favor de universidades privadas y dependencias públicas tanto nacionales como regionales. Por último, el que los mercados parciales de trabajo receptores de la migración sean los de la docencia e investigación, actividades percibidas como prestigiosas en el Departamento de Sociología de la Universidad Nacional de Colombia, sugiere que el cambio se hace, también, en busca de prestigio.

Conforme se acumula experiencia, títulos y contactos, el salario así como el tipo de contrato tiende a mejorar. Sin embargo, parece existir una barrera de cristal que mantiene al grueso de la población ajena a contrataciones laborales duraderas y bien remuneradas. Atravesar dicha barrera supone cruzar algo así como un umbral hacia un tipo de remuneración compatible con una perspectiva de largo plazo, que permite ritmos de trabajo más estables y predecibles; no hacerlo implica ritmos de trabajo agitados e inciertos con miras a lograr extender la perspectiva que permiten los ingresos percibidos. Es de suponer que así como en la docencia universitaria hay "docentes de planta", haya cargos en los demás mercados parciales de trabajo que ofrezcan sueldos profesionales y vinculaciones laborales duraderas.

Ahora bien, teniendo en cuenta que la flexibilidad, como régimen productivo, conlleva - para el caso de los mercados parciales de trabajo en los que se desempeñan los y las profesionales de Sociología- la desaparición virtual de los umbrales hacia condiciones laborales estables, quedan por esclarecer las circunstancias y características que harían posible para sociólogos y sociólogas atravesar los umbrales hacia la estabilidad.

\section{Referencias bibliográficas}

Agencia Colombiana para la Reintegración (ACR). Agencia Colombiana para la Reintegración, s/f. http://www.reintegracion.gov.co/es/agencia (último acceso: ol de septiembre de 2014).

Arango, Luz. Jóvenes en la universidad, género, clase e identidad profesional. Bogotá: Siglo del Hombre Editores, Universidad Nacional, 2006.

Arango, Luz. «La sociología como proyecto profesional y de inserción social: contrastes de género y clase». En Sociología en Colombia: balance y perspectivas, de Pedro Quintín, 175-200. Cali: Programa Editorial Universidad del Valle, 2007.

Arango, Luz, Oscar Quintero e Ivone Mendoza. «Género y origen en el acceso a la Universidad Nacional: trayectorias de estudiantes de sociología y de ingeniería de sistemas». Revista Colombiana de Sociología, n ${ }^{\circ} 22,2004$ : 87-110.

Blossfeld, Hans-Peter y Karl Mayer. «Labor Market Segmentation in the Federal Republic of Germany: An Empirical Study of Segmentation Theories from a Life Course Perspective». European Sociologica Review, Vol. 4, nº 2, 1988: 123-140. Bourdieu, Pierre y Jean Passeron. Los herederos. Buenos Aires: Siglo XXI Editores, 2009.

Cataño, Gonzalo. La sociología en Colombia: balance crítico. Bogotá: Plaza \& Janes Editores, 1986. 
Cataño, Gonzalo. «Historia de la Sociología en Colombia». En Nueva Historia de Colombia, dirigido por Álvaro Tirado, 235-246. Bogotá: Planeta, 1989.

Cataño, Gonzalo. «La Sociología en Colombia». En Sociología en Colombia: Balance y Perspectivas, de Pedro Quintín, 13-30. Cali: Programa Editorial Universidad del Valle, 2007.

Centro de Estudios Sociales. Nuestra historia, s/f. http://www.unal.edu.co/ces/ index.php/nosotros/historia (último acceso: 22 de septiembre de 2014).

Consejo Nacional de Acreditación. Lineamientos para la Acreditación de Programas de Pregrado, 2013. http://www.cna.gov.co/1741/articles-186359_pregrado_2013.pdf (último acceso: 9 de octubre de 2013).

Consejo Superior Universitario. Acuerdo 003 de 2007. "Por el cual se adiciona un parágrafo al artículo 9 del Acuerdo 016 de 2005 del Consejo Superior Universitario - Estatuto de Personal Académico de la Universidad Nacional de Colombia". Bogotá: Universidad Nacional de Colombia, 2007.

Consejo Superior Universitario. Acuerdo 045 de 2008. "Por el cual se modifica la estructura del plan de estudios del programa curricular de Sociología de la Facultad de Ciencias Humanas de la Sede Bogotá de la Universidad Nacional de Colombia, para ajustarse al Acuerdo 033 de 2007 del Consejo Superior Universitario". Bogotá: Universidad Nacional de Colombia, 2008.

Consejo Superior Universitario. Acuerdo 123. "Por el cual se adopta el Estatuto de Personal Académico de la Universidad Nacional de Colombia". Bogotá: Universidad Nacional de Colombia, 13 de noviembre de 2013.

Cubides, Fernando. «La sociología en Colombia: demandas y tribulaciones». Revista de Estudios Sociales, $\mathrm{n}^{\circ}$ 1, 1998: 9-15.

Fevre, Ralph. The Sociology of Labour Markets. Cardiff: Cardiff University, 1992.

Gómez, José. «La sociología como profesión». Revista Española de Sociología, nº 18, 2012: 125-130.

Gómez, Víctor. «Sobre la formación de competencias en el sociólogo». Revista Colombiana de Sociología, Vol. 33, $\mathrm{n}^{\circ}$ 1, 2003: 69-85.

Gómez, Yuri. Autoevaluación carrera de sociología. Bogotá: Departamento de Sociología (Sin publicar), 2009.

Granovetter, Mark. «The Strength of Weak Ties». American Journal of Sociology, Vol. 78, n 6, 1973: 1360-1380.

Martínez, Alexandra, Adriana Anacona, Teresita Sevilla y Paola Cano. «La sociología que hacen los egresados del programa de sociología de la Universidad del Valle: nuevos perfiles». En La Sociología en Colombia: balance y perspectivas, de Pedro Quintín, 201-215. Cali: Programa Editorial Universidad del Valle, 2007.

Observatorio Laboral para la Educación. Graduados Colombia, 06 de noviembre de 2013. http://www.graduadoscolombia.edu.co/html/1732/articles-334303_ documento_tecnico_2013.pdf (último acceso: ol de abril de 2015).

Páez, Guillermo. «Estado del arte de los programas de sociología en las universidades privadas de Santafé de Bogotá». En La Sociología en Colombia: estado académico, de Asociación Colombiana de Sociología, 69-110. Bogotá: ERREDICIONES, 1997.

Pedraza, Aura. «Segmentación laboral en Colombia durante el período 20012006». Revista CIFE, Vol. 18, nº 13, 2011: 101-123. 
Pontificia Universidad Javeriana. Escalafón, s/f a. http://www.javeriana.edu.co/ vicerrectoria-academica/escalafon (último acceso: 24 de agosto de 2015).

Pontificia Universidad Javeriana. Profesores Hora Cátedra, s/f b. http://www.javeriana.edu.co/vicerrectoria-academica/catedra (último acceso: 24 de noviembre de 2014).

Posso, Christian. "Calidad del empleo y segmentación laboral: un análisis para el mercado laboral colombiano». Desarrollo y Sociedad, nº 65, 2010: 191-234.

Prada, Carlos. «Análisis de los flujos de trabajadores y la segmentación laboral en Colombia». Ensayos Sobre Política Económica, Vol. 30, nº 68, 2012: 75-113.

Pries, Ludger. «Teoría sociológica del mercado de trabajo». Iztapalapa, n 42, 1997: 71-98.

República de Colombia. Código Sustantivo del Trabajo (CST). Bogotá: República de Colombia, 5 de agosto de 1950.

República de Colombia. Ley 57 de 1887. Código Civil. Bogotá: República de Colombia, 15 de agosto de 1887.

República de Colombia. Decreto 1279. Por el cual se establece el régimen salarial y prestacional de los docentes de las Universidades Estatales. Bogotá: República de Colombia, 19 de junio 2002.

República de Colombia, Ministerio del Trabajo. Decreto 2738. Por el cual se fija el salario mínimo legal. Bogotá: República de Colombia, 28 de diciembre de 2012.

Restrepo, Olga y Gabriel Restrepo. "Balance doble de treinta años de historia». En La Sociología en Colombia estado académico, de Asociación Colombiana de Sociología, 3-69. Bogotá: ERRREDICIONES, 1997.

Roberts, Helen y Diana Woodward. «Changing Patterns of Women's Employment in Sociology: 1950-80». British Journal of Sociology, Vol. 32, n 4, 1981: 531-546.

Sánchez, Cinthya. Estudiantes eternos de beca en beca. El Universal, 29 de 08 de 2007. http://www.eluniversal.com.mx/primera/29502.html (último acceso: 02 de junio de 2014).

Segura, Nora y Álvaro Camacho. «En los cuarenta años de la Sociología colombiana». Revista de Estudios Sociales, n 4, 1999: 23-35.

Sengenberger, Werner. «Dinámica de la segmentación del mercado». En Lecturas sobre el mercado de trabajo en la República Federal de Alemania: mercado de trabajo, ocupación y desempleo, 340-380. España: Ministerio de Trabajo y Seguridad Social, 1988.

Unás, Viviam. 2013. Influencia del trabajo flexible en la construcción de proyectos académicos y vida afectiva en profesores y profesoras hora cátedra. Tesis de Maestría en Sociología, Universidad del Valle.

Uribe, José, Humberto Ortíz y Gustavo García. «La segmentación del mercado laboral colombiano en la década de los noventa». Revista Economía Institucional, Vol. 9, $\mathrm{n}^{\circ}$ 16, 2007: 189-221.

Uricoechea, Fernando. «La profesionalización académica en Colombia: guías para una investigación». Revista Colombiana de Educación, $\mathrm{n}^{\circ}$ 31, 1995: 79-91.

Uricoechea, Fernando. «La sociología en Colombia: vocación, disciplina, profesión e historia». Revista Colombiana de Sociología, Vol. 6, n ${ }^{\circ}$ 1, 2001: 17-25.

Weber, Max. Ensayos sobre metodología sociológica. Buenos Aires: Amorrortu Editores, 2001.

Zuluaga, Olga. Pedagogía e Historia. Bogotá: Editorial Universidad de Antioquia, 1999. 


\section{Fuentes primarias}

\section{Entrevistas}

Diana Gómez-Casseres, 36 años, graduada en 2003, magíster. Entrevista realizada por Darío Berrío, 14/08/2014, Bogotá, Colombia.

Doris Gnecco, 38 años, graduada en 2000, magíster. Entrevista realizada por Darío Berrío, 07/09/2013, Bogotá, Colombia.

Fernanda Fernández, 33 años, graduada en 2006, profesional. Entrevista realizada por Darío Berrío, 04/09/2014, Bogotá, Colombia.

Gabriela Sandoval, 34 años, graduada en 2005, profesional. Entrevista realizada por Darío Berrío, 28/08/2014, Bogotá, Colombia.

Guillermo Landínez, años, graduado en 2010, magíster. Entrevista realizada por Juliana Ballesteros, 05/09/2013, Bogotá, Colombia.

Horacio Henao, 31 años, graduado en 2007, magíster. Entrevista realizada por Darío Berrío, 16/06/2014, Bogotá, Colombia.

Isabela Aldana, 35 años, graduada en 2003, doctora. Entrevista realizada por Mauricio Beltrán, 19/08/2015, Bogotá, Colombia.

Juliana Gómez, 33 años, graduada en 2005, magíster. Entrevista realizada por María Torres, 05/06/2014, Bogotá, Colombia.

Simón Hernández, 39 años, graduado en 2002, profesional. Entrevista realizada por Darío Berrío, 24/11/2014, Bogotá, Colombia.

Sofía Correa, 30 años, graduada en 2008, profesional. Entrevista realizada por Juliana Ballesteros y Darío Berrío, 28/08/2013, Bogotá, Colombia.

Teresa Correa, 29 años, graduada en 2008, magíster. Entrevista realizada por Juliana Ballesteros y Darío Berrío, 02/09/2013, Bogotá, Colombia.

Tomás Rojas, 24 años, graduado en 2010, profesional. Entrevista realizada por María Torres, 09/06/2014, Bogotá, Colombia. 